\title{
Temporal lobe abnormalities in dementia and depression: a study using high resolution single photon emission tomography and magnetic resonance imaging
}

Klaus P Ebmeier, Neil Prentice, Ann Ryman, Eleanor Halloran, J Ewen Rimmington, Jonathan K K Best, Guy M Goodwin

\begin{abstract}
Objectives-Perfusion SPECT and MRI were used to test the hypothesis that late onset depression is associated with brain abnormalities.

Methods-Forty depressed patients (DSM-III-R major depressive episode, not demented at two year follow up) were recruited who were either drug free, or on a stable dose of antidepressants for at least three weeks, as well as 22 demented patients (DSM-IIIR and NINCDS/ ADRDA criteria for probable Alzheimer's disease). Patients were imaged at rest with a high resolution single slice 12 detector head scanner (SME-Neuro 900) and the cerebral perfusion marker ${ }^{99 m}$ Tcexametazime (HM-PAO). Temporal lobe templates were fitted with brains pitched by $20^{\circ}-30^{\circ}$. A subgroup of 41 patients (22 depressed) were also scanned using a Siemens Magnetron 1.0 Tesla magnetic resonance imager, using a FLAIR imaging sequence for the assessment of white matter hyperintensities, and a Turbo FLASH sequence for the measurement of medial temporal lobe width.
\end{abstract}

MRC Brain

Metabolism Unit, Royal Edinburgh

Hospital, Morningside

Park, Edinburgh,

EH10 5HF, UK

K P Ebmeier

N Prentice

A Ryman

E Halloran

G M Goodwin

MRI Unit, City Hospital, Greenbank, Edinburgh, EH10 5SB, UK

J K K Best

J E Rimmington

Correspondence to: Professor K P Ebmeier, MRC Brain Metabolism Unit, Royal Edinburgh Hospital, Morningside Park, Edinburgh EH10 5HF, UK. Telephone 0131537 6534; fax 01315376110 .

Received 15 August 1996 and in final revised form 28 May 1997

Accepted 4 June 1997
Results-Demented patients showed reduced perfusion, particularly in the left temporoparietal cortex. In these regions of interest, patients with late onset depression tended to have perfusion values intermediate between patients with early onset depression and demented patients. Differences in changes in white matter between demented and early and late onset depressive patients did not reach conventional levels of significance. Temporal lobe width differed between demented and depressed patients, but not between early and late onset depressed patients. Perfusion and temporal lobe of perfusion were associated with periventricular white matter changes. Mini mental state examination scores were associated with temporal perfusion in demented patients and with changes in deep white matter in depressed patients. Finally, severity of depressive symptoms was associated with decreased perfusion in frontotemporal and basal ganglia regions of interest. width were not associated, but reductions
Conclusion-A cumulative effect of duration of illness on regional cerebral perfusion could not be confirmed. Late onset depression may show more abnormalities of deep white matter and of left temporoparietal perfusion than early onset depression, but the underlying pathology remains to be established.

(F Neurol Neurosurg Psychiatry 1997;63:597-604)

Keywords: dementia; depression; brain imaging

Depressive illness is common in elderly people. Because of its great impact on patients' quality of life and its potential reversibility, studies of aetiology and accurate diagnosis are of considerable interest. Quantitative in vivo imaging methods allow for the testing of aetiological hypotheses emphasising organic brain changes. ${ }^{1}$ If the overlap with healthy volunteers and other patient groups is small enough, scan measures can also be used for the differential diagnosis of depression with other conditions associated with cognitive impairment in old age.

Some depressed patients show structural brain changes, such as dilated ventricles and cortical atrophy. ${ }^{2-5}$ These can be associated with a late onset of the illness and an increased overall mortality. ${ }^{2}$ Recently, more localised changes in subcortical white matter and in the frontal cortex have been detected with MRI, which gives a higher resolution and greater soft tissue contrast than $\mathrm{CT}^{6-10}$ An excess of changes in white matter has been seen in late onset compared with early onset patients in a well controlled larger study, ${ }^{11}$ but not in a smaller replication study. ${ }^{10}$

Functional brain imaging studies have tended to show reduced anterior brain function in depressed patients across all ages. ${ }^{12-14} \mathrm{~A}$ first preliminary single photon emission computed tomography (SPECT) study in elderly depressed patients showed a trend towards reduced anterior brain perfusion, ${ }^{15}$ most pronounced in the dorsolateral prefrontal and anterior cingulate cortex in male patients. ${ }^{16}$ Patients with onset of illness after the age of 60 performed worse in the digit symbol substitution and the trails A test than patients with early onset, without showing greater decrements in frontal perfusion. ${ }^{16}$ 
Table 1 Patients originally depressed, but demented at follow up

\begin{tabular}{|c|c|c|c|c|c|c|}
\hline & \multicolumn{6}{|c|}{ Patients } \\
\hline & 1 & 2 & 3 & 4 & $5^{\star}$ & 6 \\
\hline Age & 74 & 71 & 69 & $80 \dagger$ & 79 & 69 \\
\hline Sex & $\mathrm{F}$ & $\mathrm{F}$ & $\mathrm{F}$ & $M$ & $\mathrm{~F}$ & $\mathrm{~F}$ \\
\hline Education (y) & 10 & 12 & 11 & 9 & 10 & 9 \\
\hline NART-IQ & $86 / 76$ & 108 & & 120 & 97 & 75 \\
\hline MMSE & $20 / 17$ & 18 & 26 & 26 & 25 & $16 / 4$ \\
\hline Hachinski & $6 / 4$ & 8 & 2 & 5 & 5 & $3 / 7$ \\
\hline Age of onset & 47 & 71 & 68 & 80 & 45 & 60 \\
\hline Hamilton & $20 / 2$ & 19 & 19 & 27 & 20 & $27 / 8$ \\
\hline Newcastle & $6 / 2$ & 8 & 4 & 7 & 9 & $9 / 0$ \\
\hline Zimmermann & & 1 & 1 & 4 & 2 & 3 \\
\hline Meguro & & 1 & 1 & 2 & 1 & 3 \\
\hline Left temporal lobe width (mm) & & 9.22 & 12.17 & 13.04 & & 14.00 \\
\hline Right temporal lobe width (mm) & & 20.12 & 10.05 & 11.05 & & 14.00 \\
\hline
\end{tabular}

$\star$ Only MRI original score/value at follow up, if available.

$\mathrm{NART}=$ revised national adult reading text; $M M S E=$ mini mental state examination .

In Alzheimer's dementia, structural and functional brain changes have been examined more extensively. Alzheimer's dementia is an important differential diagnosis of depression associated with severe cognitive impairment (pseudodementia). Similarly to depression, CT studies in Alzheimer's dementia show only non-specific global cerebral atrophy with little focal change. ${ }^{17-19}$ Functional imaging methods, such as PET and SPECT, have been more informative. In Alzheimer's dementia brain activity is most often reduced in the posterior, parietotemporal association cortex, usually bilateral, more rarely in an asymmetric fashion. Activity in the frontal association cortex is sometimes reduced in more advanced disease. ${ }^{20}$ The localisation of primary pathological changes in temporal areas ${ }^{21}$ has led to the investigation and confirmation of medial temporal lobe atrophy on CT and MRI of patients with Alzheimer's dementia. ${ }^{22-24}$ Such medial temporal changes are also observable with high resolution SPECT in patients with early dementia. ${ }^{25}$

The present study attempts to integrate some of these findings, focusing on aetiological

Table 2 Descriptive and clinical data for the three patient groups

\begin{tabular}{|c|c|c|c|c|c|}
\hline & $\begin{array}{l}\text { Early onset } \\
\text { depression }\end{array}$ & $\begin{array}{l}\text { Late onset } \\
\text { depression }\end{array}$ & Dementia & $F / \chi^{2}, P$ value & Post hoc \\
\hline \multicolumn{6}{|l|}{ Age (y): } \\
\hline Mean & 70.4 & 73.8 & 77.9 & $6.9,0.002$ & $\mathrm{ED}<\mathrm{DEM}$ \\
\hline SD & 5.6 & 5.2 & 8.6 & & \\
\hline \multicolumn{6}{|l|}{ Sex } \\
\hline Male & 7 & 7 & 8 & $0.230,89$ & \\
\hline Female & 15 & 11 & 14 & & \\
\hline \multicolumn{6}{|c|}{ Education (y): } \\
\hline Mean & 10.5 & 9.8 & 10.7 & $0.74,0.48$ & \\
\hline SD & 2.6 & 1.9 & 2.5 & & \\
\hline \multicolumn{6}{|c|}{ Premorbid IQ: } \\
\hline Mean & 99 & 102 & 103 & $0.50,0.61$ & \\
\hline SD & 15 & 13 & 12 & & \\
\hline \multicolumn{6}{|c|}{ Handedness: } \\
\hline Left & 3 & 2 & 1 & $1.3,0.51$ & \\
\hline \multirow{2}{*}{\multicolumn{6}{|c|}{ Hachinski: }} \\
\hline & & & & & \\
\hline Mean & 3.3 & 3.9 & 1 & $23.7,0.0000$ & $\mathrm{DEM}<\mathrm{ED}, \mathrm{LD}$ \\
\hline SD & 1.6 & 1.3 & 1.1 & & \\
\hline \multicolumn{6}{|c|}{ Hamilton depression scale (17 item): } \\
\hline Mean & 22.6 & 19.1 & & $5.1,0.03$ & $\mathrm{LD}<\mathrm{ED}$ \\
\hline SD & 4 & 6 & & & \\
\hline \multicolumn{6}{|c|}{ Newcastle scale: } \\
\hline Mean & 6.5 & 5.4 & & $2.4,0.13$ & \\
\hline SD & 2.2 & 2.5 & & & \\
\hline \multicolumn{6}{|c|}{ Mini mental state examination: } \\
\hline Mean & 26.8 & 26.2 & 16.8 & $38.4,0.0000$ & $\mathrm{DEM}<\mathrm{ED}, \mathrm{LD}$ \\
\hline $\mathrm{SD}$ & 3 & 1.7 & 6 & & \\
\hline
\end{tabular}

$\mathrm{ED}=$ Early depression; $\mathrm{LD}=$ late depression; $\mathrm{DEM}=$ dementia. hypotheses rather than on differential diagnosis. Three groups - patients with early and late onset depression and patients with Alzheimer's dementia - were compared using MRI to examine medial temporal lobe width and white matter hyperintensities, and SPECT in a conventional transaxial and a temporal lobe region of interest (ROI) analysis. It was our prediction (hypothesis 1) that late onset cases of depression would show signs of abnormal brain structure and function similar to Alzheimer's dementia, assuming that organic impairment was a predisposing risk factor for depression. If, on the other hand, functional impairment were a consequence of repeated depressive episodes and their treatment, early onset cases would show a more abnormal scan pattern. We further predicted (hypothesis 2) that medial temporal lobe width and perfusion could distinguish between dementia and depression. However, in depression more modest effects may be associated with the degree of cognitive impairment because floor effects would not dominate, as in Alzheimer's dementia (hypothesis 3). Finally, we predicted an excess of abnormalities in white matter in late onset depression (hypothesis 4), which would be correlated with the degree of cognitive impairment (hypothesis 5). Such a correlation was judged to be less likely in Alzheimer's dementia, in which vascular changes underlying abnormalities of white matter are not thought to be responsible for the dementia, although recent studies have indicated some contribution of vascular changes in the expression of symptomatic late onset Alzheimer's disease. ${ }^{26} 27$

\section{Subjects and methods}

DEPRESSED PATIENTS

Forty six patients fulfilling DSM-III-R criteria for a major depressive episode with or without melancholic or mood congruent psychotic features $^{28}$ were recruited into the study from referrals to the Edinburgh old age psychiatry services. Patients were clinically assessed to confirm the diagnosis and to exclude those with associated psychiatric diagnoses, such as alcohol or substance misuse. Depressive symptoms were assessed with the 17 item Hamilton depression rating scale ${ }^{29}$ and the Newcastle scale. ${ }^{30}$ Patients were also required to complete neuropsychological tests, including the mini mental state examination, ${ }^{31}$ and the national adult reading test revised. ${ }^{32}$ For scanning purposes patients were required to be either drug free or on a stable dose of antidepressant drugs for at least three weeks. Patients who had been treated with ECT within six months were excluded from the study. Hachinski ischaemia scores ranged from 1 to $8 .^{33}$ The patients formed part of a larger group recruited prospectively to study outcome in elderly depressed patients (by $\mathrm{EH}$ ). Patients found to be demented at two year follow up were excluded from the study (table 1). Patients were divided into two groups by age of onset (64/65 years) with mean ages of onset of 42.7 (SD 13.4) years and 72.8 (SD 5.0) years; table 2 shows further sociodemographic and clinical details. 
DEMENTED PATIENTS

Twenty two patients fulfilling DSM-IIIR ${ }^{28}$ and NINCDS/ADRDA criteria for Alzheimer's dementia ${ }^{34}$ were recruited from referrals to the Royal Edinburgh and Royal Victoria Hospitals. The geriatric mental state and history and aetiology schedule ${ }^{35}$ were used as the basis for a standardised diagnostic interview. Subjects were all living at home and had been diagnosed within 12 months of the time of recruitment. Mean duration of illness was retrospectively determined from all available information and was 2.2 (SD 1.1) years, range $0-4$ years. Patients with current evidence or history within the past five years of any neurological condition (including epilepsy, stroke, head injury with loss of consciousness or immediate confusion after the injury, focal brain lesion, migraine headaches) or major psychiatric disorder (including psychosis and major depression and alcohol and substance misuse) were excluded from the study. Physical investigations were carried out to exclude other causes of dementia. Patients with Hachinski ischaemia scores greater than 4 were excluded. ${ }^{33}$ Other chronic physical illness was accepted as it is a common feature in the elderly population. Additionally, patients with a previous severe allergic reaction, with kyphosis or other physical deformities making positioning in the scanner difficult, poor visual acuity, or deafness making participation in neuropsychological assessment difficult, and pacemaker or metal implant contraindicating MRI, were excluded. Informed consent of the patients and their relatives was obtained. Patients were required to complete neuropsychological tests-namely, the mini mental state examination ${ }^{31}$ and the revised national adult reading test (NART-R). ${ }^{32}$

SPECT PROTOCOL

Study protocols were approved by the Administration of Radioactive Substances Advisory Committee (ARSAC) at the UK Department of Health. All patients were imaged with a high resolution $(8.5 \mathrm{~mm})$ single slice 12 detector head scanner (Neuro 900, Strichman Medical Equipment Inc, Boston, USA). A plastic cannula was inserted into an arm vein 10-20 minutes before the injection of $500 \mathrm{MBq}$ ${ }^{99 \mathrm{~m}}$ Tc-exametazime (HM-PAO) over $30 \mathrm{sec}-$ onds. During the injection and for five minutes afterwards, subjects were lying comfortably resting on the imaging table with eyes closed and covered, and environmental noises were kept to a minimum. The head was positioned in a moulded head support, aligned with the help of two crossed lights and fixed with pressure pads over the zygomatic arches. Slices were acquired parallel to the orbitomeatal plane starting at a level about $2 \mathrm{~cm}$ above the orbitomeatal line and at $1 \mathrm{~cm}$ intervals above this level.

Two transverse slices were chosen for analysis about $4 \mathrm{~cm}$ and $6 \mathrm{~cm}$ above the orbitomeatal line. A standard template was prepared by drawing regions of interest over corresponding brain atlas slices. ${ }^{36}$ Although this atlas is oriented to an internal anatomical reference (the line between anterior and posterior commissures) the orbitomeatal line is almost parallel with it. ${ }^{37}$ The regions of interest (ROIs) include - in the lower slice-frontal, anterior cingulate, anterior temporal, posterior temporal, calcarine, and occipital cortex, as well as caudate, putamen, and thalamus. The corresponding template for the higher slice contains frontal, anterior cingulate, parietal, and occipital cortex. The templates are linearly and symmetrically deformed to fit different brain sizes and shapes using the $20 \%$ isocontour line to define the cortical edge. The reliability of this ROI method has been examined previously in both control and patient groups, with interrater errors ranging from $4 \%-25 \%$ for different ROIs, with a mean of $10 \% .^{38}$

For the fitting of temporal lobe templates, brains were pitched backwards by $20^{\circ}-30^{\circ}$ to display the temporal lobes along their longest anterior-posterior axis. Ten circular regions of interests were fitted as an ensemble to the lateral and medial cortical layers of the temporal lobes. Mean interrater errors ranged from $6 \%-30 \%$, with a mean of $16.5 \%$. Interrater reliability, and therefore the power to detect group differences, deteriorated towards the poles of the temporal lobes, probably related to variability in anatomy (figure).

Regional counts were normalised to the occipital cortex, an area that remains relatively normal in depression and dementia.
$40 \mathrm{~mm}$ above OML

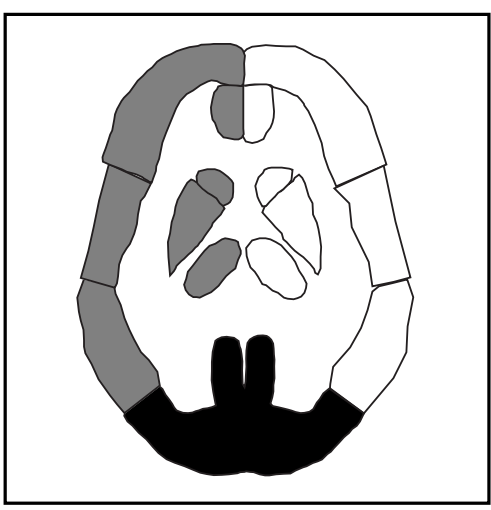

$60 \mathrm{~mm}$ above OML

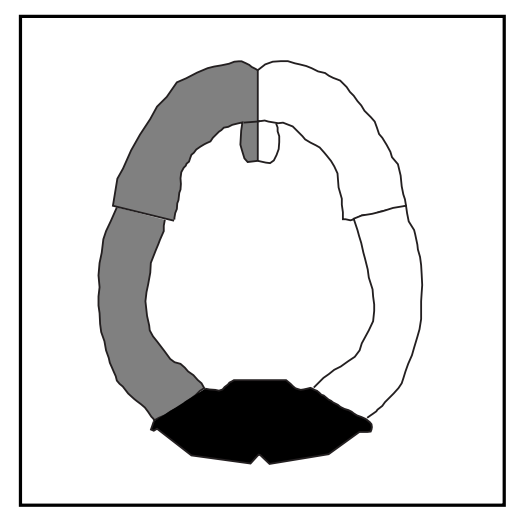

Temporal lobe template

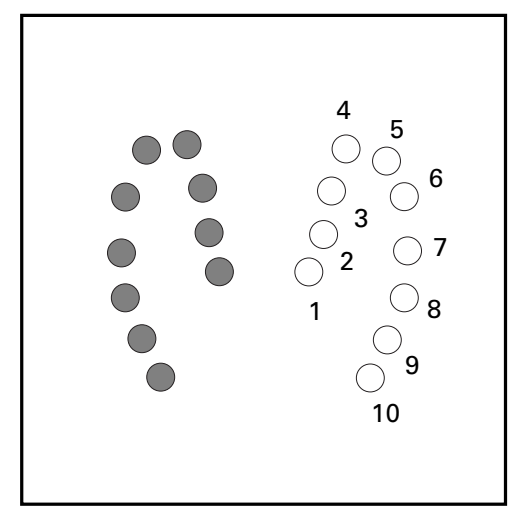

Templates applied to perfusion maps parallel to the orbitomeatal line (OML), and along the long axis of the temporal lobes. Black=reference area. 
PROTOCOL FOR MRI

Forty one patients were also scanned using a Siemens Magnetron 1.0 Tesla magnetic resonance imager. A FLAIR imaging sequence (TR 6000, TE 150, TI 2100, FOV 230, slice thickness $5 \mathrm{~mm}$, number of slices 9 , distance gap 5 $\mathrm{mm}$, acquisition time $7 \mathrm{~min} 38 \mathrm{~s}$ ) was used for the assessment of hyperintensities in white matter. FLAIR is a recent addition to the MRI repertoire of possible contrasts. ${ }^{39}$ Lesions in white matter are best visualised (in the absence of a contrast agent) with a $\mathrm{T} 2$ weighted scan, in which they are hyperintense. However, CSF is also bright, and periventricular and peripheral white matter lesions can sometimes be missed. FLAIR has been designed to give a heavily T2 weighted scan with excellent contrast, but with the CSF signal cancelled. The sequence is not implemented on Siemens Magnetom imagers. Because of the long T1 of CSF this is a long sequence. To make the collection time feasible, the second slice must start while the first slice is in progress. This requires a double loop structure not available on the Magnetom software. A programme was developed (by JER) in which the collection shift position was explicitly stated so that the loop structure was not required. As this produces fixed shifts, a selection of programmes with different values was written. FLAIR images were examined by an experienced radiologist (JKKB) and scored for periventricular and deep white matter hyperintensities using the methods proposed by Zimmerman et al ${ }^{40}$ and Meguro et al. ${ }^{41}$

A Turbo FLASH sequence (TR 10, flip angle $12^{\circ}$, TE 4, T1 200, TD 500, FOV 250, effective slice thickness $1.875 \mathrm{~mm}$, number of slices 128 , acquisition time $4 \mathrm{~min} 19 \mathrm{~s}$ ) was employed for the measurement of medial temporal lobe width. We used the ANALYZE software on a Sun SPARC workstation, following the procedure suggested for CT data by Jobst et al. ${ }^{23}$ Scans were reoriented in a plane parallel to the long axis of the temporal lobes, just as SPECT images (see above). A slice was chosen in the middle of the medial temporal lobe, taken from the last slice where cerebellum was visible to the last where brainstem was clearly visible. The narrowest width of the temporal lobe adjacent to the brain stem was determined using calipers.

\section{STATISTICS}

Dependent (scanning) variables were compared between diagnostic groups using analysis of covariance (ANCOVA) with age as a covariate. This was thought to be necessary, because the brain changes predicted were likely to be associated with greater age. Associations were modelled linearly, but also with a quadratic function of age which was to be used if a better fit could be achieved. If three-group comparisons were significant, differences between each pair of groups were examined, again controlling for age. No corrections for multiple planned comparisons were used. Correlations between measures of cognitive deterioration (MMSE) and brain measures were, again, controlled for age and computed separately for diagnostic groups. Because of the scale characteristics of the Meguro and Zimmerman scales, the non-parametric Kendall partial rank order correlation coefficient (partial $\tau$ ) was used to check the validity of the results of parametric correlations. ${ }^{42}$ Associations between SPECT and MRI measures were explored using non-parametric correlations (Spearman's $\rho$ ) across diagnostic groups. Confidence intervals for ratios were taken from "exact" confidence interval tables for the binomial distribution. ${ }^{43}$

\section{Results}

Six depressed patients were demented at follow up (table 1). Although as a group they were too few to make any statistical comparisons with the other depressed patients, half had normal MMSE scores. They were excluded from all the following analyses.

Table 2 summarises the descriptive and clinical variables for the three groups. Although all age means were within the 70 s, and age ranges were similar, depressed patients with an early onset of their illness were significantly younger than demented patients. Groups were well matched for sex, education, premorbid intelligence, and handedness. Demented patients were selected for low ischaemic index; therefore, Hachinski scores were significantly lower in this group. The early depression patients were marginally, but significantly, more depressed than the late depression patients. Although $13 \%$ of the depressed patients were cognitively impaired (MMSE<24), as a group their MMSE scores were significantly higher than those of the Alzheimer's dementia group.

CROSS SECTIONAL COMPARISONS BETWEEN EARLY DEPRESSION, LATE DEPRESSION, AND ALZHEIMER'S DEMENTIA IMAGING FINDINGS

Table 3 gives the age corrected results of the transaxial ROI analysis (for templates see figure). Here, as in all age regressions, the quadratic term generated a fit not substantially better than the linear term alone and was therefore omitted. The left posterior temporal cortex was underperfused in demented patients compared with both depressed groups, as was the left parietal cortex compared with the early onset group only. The caudate/ putamen showed significantly lower perfusion in demented than in depressed patients. This effect may be due to (anterior) ventricular dilatation and the template fitting procedure, which fits to the outline of the cortex without making more than a proportional (affine) adjustment to the central structures.

Table 4 shows the temporal lobe template perfusion results corrected for age. Reduced perfusion in demented patients could be found in region 3 (mesial), region 5 (temporal pole), and regions 6 and 7 (lateral anterior).

After age correction, there were trends for white matter changes to be more pronounced in demented, and perhaps late onset depressed patients, which did not quite reach conventional levels of significance (table 5). If the side with the narrowest temporal lobe width was taken for each patient, demented patients had significantly smaller values than depressed patients (table 5). 
Table 3 Group means (SD) for the three patient groups, traditional templates parallel to the orbitomeatal plane

\begin{tabular}{|c|c|c|c|c|c|c|c|c|c|c|}
\hline & \multicolumn{5}{|l|}{ Left } & \multicolumn{5}{|l|}{ Right } \\
\hline & $\begin{array}{l}\text { Early onset } \\
\text { depression }\end{array}$ & $\begin{array}{l}\text { Late onset } \\
\text { depression }\end{array}$ & Dementia & $\begin{array}{l}F, P \text { value; } \\
\text { age corrected }\end{array}$ & $\begin{array}{l}\text { Post hoc } \\
\text { ANCOVA }\end{array}$ & $\begin{array}{l}\text { Early onset } \\
\text { depression }\end{array}$ & $\begin{array}{l}\text { Late onset } \\
\text { depression }\end{array}$ & Dementia & $\begin{array}{l}F, P \text { value; } \\
\text { age corrected }\end{array}$ & $\begin{array}{l}\text { Post hoc } \\
\text { ANCOVA }\end{array}$ \\
\hline Number & 22 & 16 & 21 & & & 22 & 16 & 21 & & \\
\hline \multicolumn{11}{|c|}{ Frontal (4): } \\
\hline Mean & 0.93 & 0.92 & 0.89 & \multirow[t]{2}{*}{$1.23,0.30$} & & 0.92 & 0.95 & 0.91 & \multirow[t]{2}{*}{$0.81,0.45$} & \\
\hline SD & 0.09 & 0.07 & 0.06 & & & 0.09 & 0.06 & 0.14 & & \\
\hline \multicolumn{11}{|c|}{ Frontal (6): } \\
\hline Mean & 0.89 & 0.91 & 0.87 & \multirow[t]{2}{*}{$1.49,0.23$} & & 0.90 & 0.92 & 0.89 & \multirow[t]{2}{*}{$0.55,0.58$} & \\
\hline SD & 0.06 & 0.06 & 0.06 & & & 0.08 & 0.07 & 0.09 & & \\
\hline \multicolumn{11}{|c|}{ Anterior temporal (4): } \\
\hline Mean & 0.87 & 0.84 & 0.83 & \multirow[t]{2}{*}{$1.20,0.31$} & & 0.90 & 0.86 & 0.90 & \multirow[t]{2}{*}{$1.11,0.34$} & \\
\hline SD & 0.09 & 0.10 & 0.10 & & & 0.09 & 0.08 & 0.09 & & \\
\hline \multicolumn{11}{|c|}{ Posterior temporal (4): } \\
\hline Mean & 1.00 & 0.98 & 0.92 & \multirow[t]{2}{*}{$6.40,0.003$} & \multirow[t]{2}{*}{$\mathrm{ED}, \mathrm{LD}>\mathrm{DEM}$} & 0.98 & 0.97 & 0.95 & \multirow[t]{2}{*}{$0.77,0.47$} & \\
\hline SD & 0.06 & 0.05 & 0.08 & & & 0.05 & 0.07 & 0.07 & & \\
\hline \multicolumn{11}{|c|}{ Parietal (6): } \\
\hline Mean & 0.95 & 0.92 & 0.89 & \multirow[t]{2}{*}{$6.29,0.003$} & \multirow[t]{2}{*}{$\mathrm{ED}>\mathrm{DEM}$} & 0.95 & 0.92 & 0.90 & \multirow[t]{2}{*}{$2.38,0.10$} & \\
\hline SD & 0.04 & 0.06 & 0.06 & & & 0.04 & 0.07 & 0.08 & & \\
\hline \multicolumn{11}{|c|}{ Anterior cingulate (4): } \\
\hline Mean & 0.93 & 0.93 & 0.85 & \multirow[t]{2}{*}{$2.45,0.10$} & & 0.92 & 0.92 & 0.85 & \multirow[t]{2}{*}{$2.21,0.12$} & \\
\hline SD & 0.12 & 0.11 & 0.14 & & & 0.12 & 0.09 & 0.12 & & \\
\hline \multicolumn{11}{|c|}{ Anterior cingulate (6): } \\
\hline Mean & 0.91 & 0.94 & 0.97 & \multirow[t]{2}{*}{$0.67,0.52$} & & 0.90 & 0.96 & 0.96 & \multirow[t]{2}{*}{$0.98,0.38$} & \\
\hline SD & 0.14 & 0.14 & 0.14 & & & 0.14 & 0.14 & 0.12 & & \\
\hline \multicolumn{11}{|c|}{ Caudate (4): } \\
\hline Mean & 1.06 & 1.09 & 0.82 & \multirow[t]{2}{*}{$18.9,0.000$} & $\mathrm{ED}, \mathrm{LD}>\mathrm{DEM}$ & 1.04 & 1.10 & 0.76 & $31.67,0.000$ & $\mathrm{ED}, \mathrm{LD}>$ \\
\hline SD & 0.13 & 0.11 & 0.17 & & & 0.12 & 0.09 & 0.17 & & DEM \\
\hline Putamen & & & & & & & & & & \\
\hline Mean & 1.18 & 1.22 & 1.11 & $9.31,0.000$ & $\mathrm{ED}, \mathrm{LD}>\mathrm{DEM}$ & 1.17 & 1.21 & 1.11 & $4.70,0.01$ & $\mathrm{LD}>\mathrm{DEM}$ \\
\hline SD & 0.07 & 0.09 & 0.10 & & & 0.09 & 0.10 & 0.09 & & \\
\hline Thalamu & & & & & & & & & & \\
\hline Mean & 1.08 & 1.07 & 1.03 & $1.33,0.27$ & & 1.08 & 1.07 & 1.05 & $0.55,0.58$ & \\
\hline SD & 0.09 & 0.07 & 0.08 & & & 0.08 & 0.08 & 0.11 & & \\
\hline
\end{tabular}

$\mathrm{ED}=$ Early depression; $\mathrm{LD}=$ late depression; $\mathrm{DEM}=$ dementia.

Table 4 Group means (SD) for the three patient groups, temporal lobe templates parallel to the long axis of the temporal lobe

\begin{tabular}{|c|c|c|c|c|c|c|c|c|c|c|}
\hline & \multicolumn{5}{|l|}{ Left } & \multicolumn{5}{|l|}{ Right } \\
\hline & $\begin{array}{l}\text { Early onset } \\
\text { depression }\end{array}$ & $\begin{array}{l}\text { Late onset } \\
\text { depression }\end{array}$ & Dementia & $F, P$ value & $\begin{array}{l}\text { Post hoc } \\
\text { ANCOVA }\end{array}$ & $\begin{array}{l}\text { Early onset } \\
\text { depression }\end{array}$ & $\begin{array}{l}\text { Late onset } \\
\text { depression }\end{array}$ & Dementia & $F, P$ value & $\begin{array}{l}\text { Post hoc } \\
\text { ANCOVA }\end{array}$ \\
\hline Number & 22 & 16 & 21 & & & 22 & 16 & 21 & & \\
\hline \multicolumn{11}{|l|}{ Region 1: } \\
\hline Mean & 0.98 & 0.95 & 0.94 & $0.23,0.79$ & & 1.01 & 0.95 & 0.95 & $1.03,0.36$ & \\
\hline $\mathrm{SD}$ & 0.15 & 0.15 & 0.18 & & & 0.13 & 0.12 & 0.16 & & \\
\hline \multicolumn{11}{|l|}{ Region 2: } \\
\hline Mean & 0.88 & 0.80 & 0.87 & $2.18,0.12$ & & 0.88 & 0.80 & 0.83 & $0.34,0.11$ & \\
\hline $\mathrm{SD}$ & 0.12 & 0.13 & 0.13 & & & 0.11 & 0.15 & 0.09 & & \\
\hline \multicolumn{11}{|l|}{ Region 3: } \\
\hline Mean & 0.80 & 0.84 & 0.74 & $2.88,0.06$ & & 0.82 & 0.85 & 0.74 & $4.45,0.02$ & $\mathrm{LD}>\mathrm{DEM}$ \\
\hline SD & 0.13 & 0.12 & 0.13 & & & 0.14 & 0.09 & 0.11 & & \\
\hline \multicolumn{11}{|l|}{ Region 4: } \\
\hline Mean & 0.76 & 0.81 & 0.76 & $1.86,0.17$ & & 0.74 & 0.79 & 0.73 & $1.45,0.24$ & \\
\hline $\mathrm{SD}$ & 0.12 & 0.09 & 0.10 & & & 0.09 & 0.10 & 0.09 & & \\
\hline \multicolumn{11}{|l|}{ Region 5: } \\
\hline Mean & 0.90 & 0.88 & 0.78 & $5.03,0.01$ & $\mathrm{ED}, \mathrm{LD}>\mathrm{DEM}$ & 0.85 & 0.89 & 0.78 & $3.94,0.03$ & $\mathrm{LD}>\mathrm{DEM}$ \\
\hline SD & 0.14 & 0.12 & 0.12 & & & 0.12 & 0.13 & 0.09 & & \\
\hline \multicolumn{11}{|l|}{ Region 6: } \\
\hline Mean & 1.02 & 1.01 & 0.93 & $3.88,0.03$ & $\mathrm{ED}, \mathrm{LD}>\mathrm{DEM}$ & 1.03 & 1.03 & 0.95 & $3.81,0.03$ & $\mathrm{ED}, \mathrm{LD}>\mathrm{DEM}$ \\
\hline SD & 0.11 & 0.10 & 0.10 & & & 0.11 & 0.12 & 0.09 & & \\
\hline \multicolumn{11}{|l|}{ Region 7: } \\
\hline Mean & 1.06 & 1.04 & 0.96 & $3.21,0.04$ & $\mathrm{ED}>\mathrm{DEM}$ & 1.08 & 1.10 & 1.01 & $2.64,0.08$ & \\
\hline $\mathrm{SD}$ & 0.10 & 0.13 & 0.11 & & & 0.11 & 0.13 & 0.12 & & \\
\hline \multicolumn{11}{|l|}{ Region 8: } \\
\hline Mean & 1.10 & 1.11 & 1.09 & $0.26,0.77$ & & 1.09 & 1.12 & 1.07 & $1.50,0.23$ & \\
\hline SD & 0.09 & 0.08 & 0.11 & & & 0.09 & 0.10 & 0.10 & & \\
\hline \multicolumn{11}{|l|}{ Region 9: } \\
\hline Mean & 1.07 & 1.06 & 1.06 & $0.07,0.93$ & & 1.06 & 1.06 & 1.05 & $0.02,0.98$ & \\
\hline $\mathrm{SD}$ & 0.09 & 0.08 & 0.08 & & & 0.09 & 0.09 & 0.08 & & \\
\hline \multicolumn{11}{|l|}{ Region 10: } \\
\hline Mean & 1.04 & 1.06 & 1.01 & $1.95,0.15$ & & 1.07 & 1.04 & 1.04 & $0.69,0.51$ & \\
\hline SD & 0.09 & 0.07 & 0.08 & & & 0.08 & 0.09 & 0.10 & & \\
\hline
\end{tabular}

$\mathrm{ED}=$ Early depression; $\mathrm{LD}=$ late depression; $\mathrm{DEM}=$ dementia.

There were five significant comparisons between the three groups for the left and three for the right temporoparietal cortex (tables 3, 4 , and 5). Although there were no significant differences between the two depressed groups, it is striking that on the left side the late depression mean values ranged between early depression and dementia, whereas on the right side the late depression means were equal or higher than the means.

The number of partial (age corrected) positive correlations between MMSE and SPECT measures did not exceed random expectation $(2 / 42=5 \%)$ in depressed patients, but did in 
Table 5 MRI measures for the three patient groups

\begin{tabular}{|c|c|c|c|c|}
\hline & $\begin{array}{l}\text { Early onset } \\
\text { depression }\end{array}$ & $\begin{array}{l}\text { Late onset } \\
\text { depression }\end{array}$ & Dementia & $F, P$ value \\
\hline Number & 13 & 11 & 20 & \\
\hline \multicolumn{5}{|c|}{ Periventricular white matter changes: } \\
\hline Mean & 1.76 & 1.89 & 2.7 & \multirow[t]{2}{*}{$2.76,0.08$} \\
\hline SD & 1.03 & 1.04 & 1.16 & \\
\hline \multicolumn{5}{|c|}{ Deep white matter changes: } \\
\hline Mean & 1.27 & 1.99 & 2.02 & \multirow[t]{3}{*}{$2.96,0.06$} \\
\hline SD & 0.83 & 1.1 & 0.51 & \\
\hline Number & 12 & 8 & 19 & \\
\hline \multicolumn{5}{|c|}{ Left medial temporal lobe width: } \\
\hline Mean & 13.5 & 14.7 & 10.7 & \multirow{2}{*}{$1.17,0.32$} \\
\hline SD & 4.9 & 5.6 & 7.7 & \\
\hline \multicolumn{5}{|c|}{ Right medial temporal lobe width: } \\
\hline Mean & 14.8 & 15.2 & 11.2 & \multirow[t]{2}{*}{$1.65,0.21$} \\
\hline SD & 6 & 8.4 & 6.7 & \\
\hline \multicolumn{5}{|c|}{ Minimum medial temporal lobe width: } \\
\hline Mean & 12.1 & 12.6 & 7.1 & \multirow[t]{2}{*}{$6.18,0.005$} \\
\hline SD & 4.8 & 6.1 & 3.3 & \\
\hline
\end{tabular}

demented patients $(8 / 42=19 \%, 95 \%$ confidence interval (95\% CI) $9-34 \%$ ), in whom they occurred mainly in temporal ROIs. The Hamilton depression score was negatively correlated with temporal, basal ganglia, and frontocingulate ROIs $(12 / 42=29 \%, 95 \%$ CI $16-45 \%)$. There were no correlations between width of the medial temporal lobe and MMSE. Severity scores for deep white matter lesions ${ }^{41}$ were negatively correlated with MMSE in the depressed group after controlling for age (partial $r=-0.42, \mathrm{df}=23, \mathrm{P}=0.02)$.

Correlations across groups between medial temporal lobe width and SPECT measures were no more common than expected by chance $(1 / 84=1 \%)$, nor were those with deep white matter lesions $(3 / 42=7 \%, 95 \%$ CI $2-20 \%)$. There was, however, a significant number $(7 / 42=17 \%, 95 \%$ CI $7-31 \%)$ of negative correlations between changes in periventricular white matter ${ }^{40}$ and SPECT measures across all patients - that is, perfusion in the caudate, parietal, and left anterior temporal cortex including ROI 3 and right thalamus.

\section{Discussion}

There was no overall difference between the late onset and the early onset group, not supporting our prediction that patients with late onset depression would show more abnormal brain scans than those with early onset (hypothesis 1). In measures in which demented patients had abnormally reduced values (tables 4 and 5), both depressed groups had higher values. In the left temporoparietal cortex the perfusion values for the late onset group were between those of the early onset and demented patients. This suggests that the functional or anatomical changes leading to dementia and late onset depression may be partially colocalised.

\section{PERFUSION MEASURES IN WHOLE BRAIN}

TEMPLATES

Whereas the abnormalities in basal ganglia in demented patients were probably an artefact of ventricular dilatation (see above), the decrease in perfusion in Alzheimer's dementia, particularly in temporal cortex ROIs and also in the (left) parietal cortex, supports previous results. ${ }^{20}$ The absence of frontal reductions in perfusion in the patients with Alzheimer's dementia compared with the depressed groups is consistent with the relatively short duration of illness in the Alzheimer's dementia group, ${ }^{20}$ and with the previously reported frontal reduction in some depressed patients. ${ }^{1516}$

PERFUSION MEASURES IN TEMPORAL LOBE TEMPLATES

Patients with late onset depression tended to have more abnormal perfusion values in the temporal lobe than early onset patients (table 4). This suggests that the duration of the illness process has little impact on brain pathology and function. It has been argued that chronic hypercortisolaemia in depressed patients may be associated with hippocampal atrophy, but the evidence for this is weak and contradictory. ${ }^{44-46}$ The data from this study would certainly be more consistent with the notion that duration of illness has no cumulative effect on regional temporal lobe perfusion.

In the temporal lobe ROI analysis, demented patients showed abnormalities in various areas, but in particular in anterior medial (region 3, hippocampus), and anterior lateral (regions 5-7, temporal neocortex) ROIs. This result is consistent with previous SPECT studies showing hippocampal hypoperfusion in demented patients. $^{25} 47$

\section{HIPPOCAMPAL ATROPHY}

Minimal width of the medial temporal lobe was significantly smaller in demented patients (hypothesis 2), confirming a recent semiquantitative study, ${ }^{48}$ which found that anterior hippocampal atrophy classified $84 \%-89 \%$ of cases correctly as demented or depressed. We also found that hippocampal atrophy was unrelated to age of onset or cognitive impairment in depression (hypothesis 3). Whereas other structural measures, such as general cerebral atrophy and ventricular dilatation, seem to show similar overlapping changes in depression of old age and Alzheimer's dementia, ${ }^{2-5}$ we can give a cautious endorsement to the use of medial temporal lobe width to differentiate depression from established dementia in old age. The inherent lack of reliability of such a one dimensional interactive brain measure makes the development and adoption of three dimensional automated techniques desirable. We were not able to confirm the association of structural medial temporal lobe atrophy with the typical perfusion changes in the parietotemporal cortex reported previously in Alzheimer's dementia. ${ }^{23}$

CHANGES IN WHITE MATTER AND THEIR CORRELATES

By contrast with the recent report by Fujikawa et $a l,{ }^{11}$ we could not show a significant age corrected excess of deep white matter lesions in late compared with early onset depression (hypothesis 4). It is possible that greater numbers of subjects will be required to show such an effect. Cognitive impairment in depression, but not dementia, was correlated with more extensive changes in deep white matter, 
supporting the theory that cerebrovascular changes might be responsible for cognitive impairment in depression, but not in Alzheimer's dementia (hypothesis 5). In healthy volunteers, such correlations have been found for certain measures of speed and more complex mental processing, suggesting possible subclinical effects of changes in white matter. ${ }^{49} 50$

\section{Conclusion}

In summary, there is no evidence from our data for greater cumulative brain damage in early onset depression, whether due to effects of illness, such as high cortisol concentrations, or treatment by drugs or ECT. Changes seen in MRI and SPECT cannot be defined in pathological terms until postmortem, but likely candidates for temporal hypoperfusion and changes in white matter are cerebrovascular changes due to aging ${ }^{51-57}$ and organic dementias such as Alzheimer's dementia. ${ }^{25}$ The sharing of one or more of these factors by many patients with early and late onset depression and also with Alzheimer's dementia, would predict an overlap in image appearance and measures between diagnostic groups. Our results may, therefore, provide pointers towards possible aetiological factors underlying depression in old age, but for the development of diagnostic instruments that can differentiate pseudodementia from Alzheimer's dementia, large prospective studies with postmortem follow up will be necessary.

$\mathrm{NP}$ and AR were funded by Gordon Small and Scottish Hospital Endowments Research Trust (SHERT) Fellowships. Dr David Porter (Siemens, UK) helped with writing the FLAIR sequence. We thank the Wellcome Trust for financial support, $\mathrm{C}$ Murray, $M$ van Beck, N Dougall, and C Sidey for expert clinical and technical help, and $\mathrm{N}$ Brearley for the careful preparation of the manuscript. 1 Post $\mathrm{F}$. The factor of ageing in affective illness. In: Coppen A, Walk A, ed. Recent developments in affect

2 Jacoby RJ, Levy R, Bird JM. Computed tomography and the outcome of affective disorder: a follow-up study of elderly patients. Br F Psychiatry 1981;139:288-92.

3 Dolan RJ, Calloway SP, Mann AH. Cerebral ventricular size in depressed subjects. Psychol Med 1985;15:873-8.

4 Dolan RJ, Calloway SP, Thacker PF, Mann AH The cerebral cortical appearance in depressed subjects. Psycho Med 1986;16:775-9.

5 Alexopoulos GS, Young RC, Shindledecker RD. Brain computed tomography findings in geriatric depression and primary degenerative dementia. Biol Psychiatry 1992;31:591-

6 Krishnan KRR, Goli V, Ellinwood EH, France RD, Blazer DG, Nemeroff CB. Leukoencephalopathy in patients diagnosed as major depressive. Biol Psychiatry 1988;23:519-22.

7 Coffey CE, Figiel GS, Djang WT, Cress M, Saunders WB, Weiner RD. Leukoencephalopathy in elderly depressed Weiner RD. Leukoencephalopathy in elderly depressed
patients referred for ECT. Biol Psychiatry 1988;24:143-61.

8 Coffey CE, Figiel GS, Djang WT, Weiner RD. Subcortical hyperintensity on magnetic resonance imaging: a comparison of normal and depressed elderly subjects. $A m \mathcal{F}$ Psychiatry 1990;147:187-9.

9 Coffey CE, Wilkinson WE, Weiner RD, Parashos IA, Djang WT, Webb MC, et al. Quantitative cerebral anatomy in depression. Arch Gen Psychiatry 1993;50:7-16.

10 Churchill CM, Priolo CV, Nemeroff CB, Ranga K, Krishnan R, Breitner JCS. Occult subcortical magnetic resonance findings in elderly depressives. In: Murphy E, Alexopoulos G, eds. Geriatric psychiatry: key research topics for clinicians. Chichester: John Wiley, 1995:202-6.

11 Fujikawa T, Yamawaki S, Touhouda Y. Incidence of silent cerebral infarction in patients with major depression. Stroke 1993;24:1631-4.

12 Baxter LR, Schwartz JM, Phelps ME, Mazziotta JC, Guze $\mathrm{BH}$, Selin CE, et al. Reduction of prefrontal cortex glucose
metabolism common to three types of depression. Arch Gen metabolism common to thre
Psychiatry 1989;46:243-50.
13 Sackeim HA, Prohovnik I, Moeller JR, Brown RP, Apter S, Prudie J, et al. Regional cerebral blood flow in mood disorders. I. Comparison of major depressives and normal controls at rest. Arch Gen Psychiatry 1990;47:60-70.

14 Bench CJ, Friston KJ, Brown RG, Scott LC, Frackowiak RSJ, Dolan RJ. The anatomy of melancholia-focal abnormalities of cerebral blood flow in major depression. Psychol Med 1992;22:607-15.

15 Upadhyaya AK, Abou-Saleh MT, Wilson K, Grime SJ, Critchley M. A study of depression in old age using singlephoton emission computerised tomography. Br 7 Psychiatry 1990;157:76-81.

16 Curran SM, Murray CM, Van Beck M, Dougall N, O'Carroll RE, Austin M-P, et al. A single photon emission computerised tomography study of regional brain function in elderly patients with major depression and with Alzheimer-type dementia. Br f Psychiatry 1993;163:15565

17 Jacoby RJ, Levy R. Computed tomography in the elderly. III. Affective disorder. Br F Psychiatry 1980a;136:270-5.

18 Jacoby RJ, Levy R, Dawson JM. Computed tomography in the elderly. I. The normal population. Br f Psychiatry 1980; 136:256-69.

19 Jacoby RJ, Levy R. Computed tomography in the elderly. II. Senile dementia: diagnosis and functional impairment. $\mathrm{Br} \mathcal{F}$ Psychiatry 1980b;136:249-55.

20 Minoshima S, Frey KA, Koeppe RA, Foster NL, Kuhl DE. A diagnostic approach in Alzheimer's disease using A diagnostic approach in Alzheimer's disease using three-dimensional stereotactic surface projctions
fluorine-18-FDG PET. 7 Nucl Med 1995;36:1238-48.

21 Vanhoesen GW, Solodkin A. Cellular and systems neuroanatomical changes in Alzheimer's disease. Ann NY Acad Sci 1994;747:12-35.

22 Scheltens P, Leys D, Barkhof F, Huglo D, Weinstein HC, Vermersch $\mathrm{P}$, et al. Atrophy of medial temporal lobes on MRI in "probable" Alzheimer's disease and normal ageing: diagnostic value and neuropsychological correlates. $\mathcal{f} \mathrm{Neu}$ rol Neurosurg Psychiatry 1992;55:967-72.

23 Jobst KA, Smith AD, Parker CS, Wear A, King EM, Smith A, et al. Association of atrophy of the medial temporal lobe with reduced blood flow in the posterior parietotemporal cortex in patients with a clinical and pathological diagnosis of Alzheimer's disease. I Neurol Neurosurg Psychiatry 1992; 55:190-4.

24 Jobst KA, Smith AD, Szatmari M, Esiri MM, Jaskowski A, Hindley N, et al. Rapidly progressing atrophy of medial temporal lobe in Alzheimer's disease. Lancet 1994;343: 829-30.

25 Ohnishi T, Hoshi H, Nagamachi S, Jinnouchi S, Flores LG, Futami S, et al. High-resolution SPECT to assess hippocampal perfusion in neuropsychiatric diseases. $7 \mathrm{Nucl} \mathrm{Med}$ 1995;36:1163-9.

26 Claus JJ, Breteler MMB, Hasan D, Krenning EP, Bots ML, Grobbee DE, et al. Vascular risk factors, atherosclerosis, cerebral white matter lesions and cerebral perfusion in a population-based study. Eur 7 Nucl Med 1996;23:675-82.

27 Snowdon DA, Greiner LH, Mortimer JA, Riley KP, Greiner PA, Markesbery WR. Brain infarction and the clinical expression of Alzheimer disease-the nun study. $\mathscr{F} A M A$ 1997;277:813-7.

28 American Psychiatric Association. Diagnostic and statistical manual of mental disorders, 3rd ed, revised. Washington, DC: APA, 1987

29 Hamilton M. Rating scale for depression. $\mathcal{F}$ Neurol Neurosurg Psychiatry 1960;23:56-62.

30 Carney MPW, Roth M, Garside RF. The diagnosis of depressive syndromes and the prediction of ECT response. $1965 ; 111: 659-74$

31 Folstein MF, Folstein SE, McHugh PA. Mini-mental state: a practical method for grading the cognitive state of patients for the clinician. I Psychiatr Res 1975;12: 89-98.

32 Nelson HE, Willison JR. The revised national adult reading test - test manual. Windsor, UK: NFER-Nelson, 1991.

33 Hachinski VC, Iliff CD, Zilkla E. Cerebral blood flow in dementia. Arch Neurol 1975;32:632-7.

34 McKhann G, Drachman D, Folstein M, Katzman R, Price D, Stadlan E. Clinical diagnosis of Alzheimer's disease: report of the NINCDS-ADRDA work group under the auspices of the Department of Health and Human Task Force in Alzheimer's disease. Neurology 1984;34:939-44.

35 Copeland JRM, Dewey ME. Neuropsychological diagnosis (GMS-HAS-AGECAT package). International fournal of Psychogeriatrics 1991;3:43-9.

36 Talairach J, Zilkha G, Tournoux P, Prosalentis A, BordasFerrier M, Covello L, et al. Atlas d'Anatomie Stereotactique du Telencephale Paris: Masson, 1988.

37 Szikla G, Bouvier G, Hori T, Petrov V. Angiography of the human brain cortex. Berlin: Springer, 1977.

38 Ebmeier KP, Dougall NJ, Austin M-P, Murray CL, Curran SM, O'Carroll R, et al. The split-dose technique for the study of psychological and pharmacological activation with the cerebral blood flow marker exametazime and single photon emission computed tomography (SPECT): reproducibility and rater reliability. International fournal of Methods in Psychiatric Research 1991;1: $27-38$.

39 Hajnal JV, de Coene B, Baudouin CJ, Young IR, Bydder GM. MRI of the brain and spinal chord using fluid attenuated inversion recovery (FLAIR) pulse sequences. Clinical Magnetic Resonance Imaging 1993;3:35-9.

40 Zimmerman RD, Fleming CA, Lee BCP, Saint-Louis LA, Deck MDF. Periventricular hyperintensity as seen by mag- 
netic resonance: prevalance and significance. Am $\mathcal{F}$ Radiol 1986;146:443-50.

41 Meguro K, Yamaguchi T, Hishinuma T, Miyazawa H, Ono $\mathrm{S}$, Yamada $\mathrm{K}$, et al. Periventricular hyperintensity on magnetic resonance imaging correlated with brain ageing and atrophy. Neuroradiology 1993;35:125-9.

42 Siegel S, Castellan NJ. Nonparametric statistics for the behavioral sciences, 2nd ed. New York: McGraw-Hill Book, 1988 : 254-61.

43 Diem K, Lentner C. Documenta Geigy scientific tables, 7th ed. Macclesfield: Geigy Pharmaceuticals, 1970.

44 Axelson DA, Doraiswamy PM, McDonald WM, Boyko OB, Tupler LA, Patterson LJ, et al. Hypercortisolemia and hippocampal changes in depression. Psychiatry Res 1993;47: 163-73.

45 Coffey CE, Wilkinson WE, Weiner RD, Ritchie JC, Aque M The dexamethasone suppression test and quantitative cer-
ebral anatomy in depression. Biol Psychiatry 1993b;33:442ebral

46 O'Brien JT, Ames D, Schweitzer I, Colman P, Desmond P, Tress B. Clinical and magnetic resonance imaging correlates of hypothalamic-pituitary-adrenal axis function in depression and Alzheimer's disease. Br F Psychiatry 1996 (in press).

47 Wolfe N, Reed BR, Eberling JL, Jagust WJ. Temporal lobe perfusion on single photon emission computed tomography predicts the rate of cognitive decline in Alzheimer's disease. Arch Neurol 1995;52:257-62.

48 O'Brien JT, Desmond P, Ames D, Schweitzer I, Tuckwell V, Tress $\mathrm{B}$. The differentiation of depression from dementia by temporal lobe magnetic resonance imaging. Psychol Med 1994;24:633-40.
49 Schmidt R, Fazekas F, Offenbacher H, Dusek T, Zach E, Reinhart B, et al. Neuropsychologic correlates of MRI Reinhart B, et al. Neuropsychologic correlates of MRI white matter hyperintensities: a st

50 Tupler LA, Coffey CE, Logue PE, Djang WT, Fagan SM. Neuropsychological importance of subcortical white matter hyperintensity. Arch Neurol 1992;49:1248-52.

51 Eberling JL, Reed BR, Nordahl TE, Budinger TF, Kusubov $\mathrm{N}$, Jagust WJ. Reduced temporal lobe glucose metabolism in aging. 7 Neuroimaging 1995;5:178-82.

52 George AE, deLeon MJ, Kalnin A, Rosner L, Goodgold A, Chase N. Leukoencephalopathy in normal and pathologic aging, 1. CT study of brain leucencies. Am $\mathcal{F}$ Neuroradiol 1986;7:561-6.

53 Omerod IEC, Miller DH, McDonald WI, DuBoulay EPGH, Rudge P, Kendall BE. The role of NMR imaging in the assessment of multiple sclerosis and isolated the assessment of multiple sclerosis and

54 Awad IA, Spetzler RF, Hodak JA, Awad CA, Carey R. Incidental subcortical lesions identified on magnetic resonance dental subcortical lesions identified on magnetic resonance cerebrovascular risk factors. Stroke 1986;17:1084-9.

55 Gerard G, Weisberg L. MRI periventricular lesions in adults. Neurology 1986;36:998-1001.

56 Erkinjuntti T, Ketonen L, Sulkava R, Sipponen J, Vuorialho $M$, Hvanainen $M$. Do white matter changes on MRI and CT differentiate vascular dementia from Alzheimer's disease? F Neurol Neurosurg Psychiatry 1987; 50:37-42

57 Hershey LA, Modic MT, Greenough PG, Jaffe DF. Magnetic resonance imaging in vascular dementia. Neurology 1987;37:29-36.

\section{Fournal of Neurology Neurosurgery and Psychiatry - http://www.jnnp.com}

Visitors to the world wide web can now access the Fournal of Neurology Neurosurgery and Psychiatry either through the BMJ Publishing Group's home page (http://www.bmjpg.com) or directly by using its individual URL (http://www.jnnp.com). There they will find the following:

- Current contents list for the journal

- Contents lists of previous issues

- Members of the editorial board

- Subscribers' information

- Instructions for authors

- Details of reprint services.

A hotlink gives access to:

- BMJ Publishing Group home page

- British Medical Association web site

- Online books catalogue

- BMJ Publishing Group books.

The web site is at a preliminary stage and there are plans to develop it into a more sophisticated site. Suggestions from visitors about features they would like to see are welcomed. They can be left via the opening page of the BMJ Publishing Group site or, alternatively, via the journal page, through "about this site". 